\title{
Frenzy Sneakers after Market: From Price Control to Block Chain
}

\author{
Weihao Zhu1, Maogang Tang2 ${ }^{2}$, Yang Yue ${ }^{1}$ \\ ${ }^{1}$ No. 2 High School of East China Normal University, Shanghai, China \\ ${ }^{2}$ School of Business, East China University of Science and Technology, Shanghai, China \\ Email: `tangmaogang@126.com, ${ }^{\star}$ zhuwei_hao@163.com, ${ }^{\star} 2523088200 @ q q . c o m$
}

How to cite this paper: Zhu, W. H., Tang, M. G., \& Yue, Y. (2020). Frenzy Sneakers after Market: From Price Control to Block Chain. Open Journal of Social Sciences, 8 , 270-282.

https://doi.org/10.4236/jss.2020.810018

Received: September 30, 2020

Accepted: October 26, 2020

Published: October 29, 2020

Copyright $\odot 2020$ by author(s) and Scientific Research Publishing Inc. This work is licensed under the Creative Commons Attribution International License (CC BY 4.0).

http://creativecommons.org/licenses/by/4.0/

\begin{abstract}
Speculators appear during the flourishing age of the sneaker trading tide, trying to profit from it by affecting the price of sneakers, which invokes discussions about how to eliminate the price premium. We conducted a survey to analyze the need for most consumers aged 15-45 and found the biggest problem that most consumers care about: transaction transparency. Statistical data of more than 1000 pairs of shoes collected from the second biggest sneaker platform Nice also proves the correlation between sneakers' price and price influential factors-release time and demand-obey the basic price mechanism. An interview with the industry insider also takes a deeper perspective into the market structure. However, through our research, we supposed increasing transaction transparency through block chain should be the priority, so that we can keep pushing the flourishing market.
\end{abstract}

\section{Keywords}

Block Chain, Sneaker Market, Sneaker Trading Platform, Price-Premium, Transaction Transparency, Consumption

\section{Introduction}

The Sneaker market has been developing since 1917, and the general trend of the sneaker market is that a pair of shoes is no longer limited to wearing functions, but gradually transformed into a fashionable product, which can even be used for collection, investment, and secondary trading. As of September 2019, China's trendy brands' consumption growth rate has reached $62 \%$, which is 3.7 times that of non-trendy brands. Ali's data also shows that the search volume of fashionable brands has increased by more than $60 \%$, and the sales have increased by $260 \%$. Also, the global sneaker market is worth six billion dollars, where China obtains 
1/6 of it (https://tech.sina.com.cn/roll/2020-02-25/doc-iimxyqvz5692240.shtml). With the huge GMV and transaction volume from two main trading platforms, Poizon and Nice (two of the biggest sneaker-trading platform in China, which had 15.3 billion yuan and 83 billion yuan for their GMV from 7.16.2017 - 7.15.2019), "price premium" in the secondary market of sneakers has drawn much attention. For instance, a size 8.5 co-branded AJ1 between Nike and famous rapper Travis Scott had an original price of $¥ 1299$. In three months, the price in the secondary market soared to $¥ 15,000$, which means the premium rate exceeded 1000\% (https://www.huxiu.com/article/312230.html). Undoubtedly, the stunning price-premium of a pair of shoes creates a buzz. People feel uncomfortable with the sudden raise of a pair of shoes that they wear on their feet. We took the same question to research on the rationality of the price premium, through statistical technique and deep interviews with different perspectives in the sneaker market, and we finally reached out to the most acute issue-transaction transparency.

According to our survey by sending questionnaires to our friends and relatives aged from 15 to 45, we have received 332 effective responding answers. Among the responders, $70.78 \%$ of them have considered purchasing sneakers on secondary trading platforms, $10 \%$ of them believe that they will lose interest in purchasing sneakers if the truth or falsehood of sneakers cannot be ensured, and nearly $50 \%$ of them would choose their favorite secondary platform based on low rate of getting fake sneakers, which demonstrates that from consumers' perspectives, buying a fake pair of shoes is much serious than buying shoes with price premium.

To explore whether price premium is necessary and rational to solve, this paper applies statistical analysis of 1000 pairs of shoes from Nice, to conduct a correlation and regression analysis, which proved the normality of the current sneaker market.

Additionally, we analyzed a few methods on controlling price premium on sneaker trading platforms but finding downsides which may do harm to the long-period development of the sneaker market. Considering the total volume of trading on Nice and Poison was estimated over 1.8 billion in 2019, the paper was of effectiveness, and the paper also provided methods to solve this problem as well, which is the use of block chain, so that the sneaker trading platform can improve itself and keep going forward on its path.

\section{Questionnaire Survey}

The questionaire is designed and distributed through the platform WJX.cn, and the sampling population of this survey covers 332 people aged 15 - 45 in Shanghai. This survey may have its limitations as the sampling population is voluntary acquaintances of the authors instead of randomly selected. The multiple-choice questions asked aimed for general opinions from the consumers' perspective and how their habits and ideas reveal certain truths about the sneakers aftermarket. Some of the questions' proportions below exceed $100 \%$ because they can choose more than one option. 
Question \#1: Do you buy fashionable sneakers from Nike, Adidas, or other designer brands? If so, what is the reason why you buy them?

\begin{tabular}{lcc}
\hline \multicolumn{1}{c}{ Options } & $\begin{array}{c}\text { Number } \\
\text { of people }\end{array}$ & Proportion \\
\hline $\begin{array}{l}\text { I do buy them because I like sneakers, } \\
\text { and I pay attention to the sneakers } \\
\text { market and the fashion industry. }\end{array}$ & 63 & $18.98 \%$ \\
$\begin{array}{l}\text { I regularly buy them because } \\
\text { sneakers are cool. }\end{array}$ & 26 & $7.83 \%$ \\
$\begin{array}{l}\text { I occasionally buy sneakers that } \\
\text { I especially like. }\end{array}$ & 112 & $33.73 \%$ \\
$\begin{array}{l}\text { I rarely buy sneakers because they } \\
\text { are too expensive }\end{array}$ & 29 & $8.73 \%$ \\
$\begin{array}{l}\text { I rarely buy sneakers because } \\
\text { I am afraid of buying fake ones }\end{array}$ & 5 & $1.51 \%$ \\
$\begin{array}{l}\text { I almost never buy sneakers, } \\
\text { and I am unfamiliar with them }\end{array}$ & 97 & $29.22 \%$ \\
$\quad$ Total & 332 & \\
\hline
\end{tabular}

About $70.78 \%$ of the people buy sneakers while $10.24 \%$ of them don't buy sneakers for a reason and implies a demand for an improvement of the sneakers market (options marked red). The sneakers aftermarket is indeed popular but flawed from the consumers' perspective.

Question \#2: What is your opinion on price premium of sneakers?

\begin{tabular}{lccc}
\hline \multicolumn{1}{c}{ Options } & $\begin{array}{c}\text { Number } \\
\text { of people }\end{array}$ & Proportion & \\
\hline $\begin{array}{l}\text { I am extremely against price premium } \\
\text { of sneakers because I cannot afford } \\
\text { certain sneakers anymore. }\end{array}$ & 114 & $48.51 \%$ \\
$\begin{array}{l}\text { I will buy sneakers regardless of } \\
\text { their price premium }\end{array}$ & 58 & $24.68 \%$ \\
$\begin{array}{l}\text { I will not buy sneakers that } \\
\text { has price premium }\end{array}$ & 43 & $18.3 \%$ \\
$\begin{array}{l}\text { I advocate price premium because the } \\
\text { more expensive the more valuable. }\end{array}$ & 20 & $8.51 \%$ \\
\multicolumn{1}{c}{ Total } & 235 & \\
\hline
\end{tabular}

Almost half (48.51\%) of the people surveyed are against price premium because of financial reasons.

Question \#3: What do you think is your maximum tolerance for a pair of sneaker's price premium? 


\begin{tabular}{lccc}
\hline \multicolumn{1}{c}{ Options } & $\begin{array}{c}\text { Number } \\
\text { of people }\end{array}$ & Proportion & \\
\hline $\begin{array}{l}\text { No tolerance for more than original } \\
\text { Price }\end{array}$ & 99 & $42.13 \%$ \\
2-3 times the original price & 79 & $33.62 \%$ \\
3-5 times the original price & 16 & $6.81 \%$ \\
5 times the original price or more & 4 & $1.7 \%$ \\
$\begin{array}{l}\text { Price is not important, and I buy } \\
\text { whichever I like }\end{array}$ & 37 & $15.74 \%$ \\
\multicolumn{1}{c}{ Total } & 235 & \\
\hline
\end{tabular}

$42 \%$ of the people can only tolerate the original price, and $40.43 \%$ of them can tolerate a price premium of less than 5 times the original price.

Question \#4: What is your opinion on sneaker sellers?

\begin{tabular}{lccc}
\multicolumn{1}{c}{ Options } & $\begin{array}{c}\text { Number } \\
\text { of people }\end{array}$ & Proportion & \\
\hline $\begin{array}{l}\text { I hate sellers who only sell sneakers } \\
\text { for profit and know nothing } \\
\text { about the culture }\end{array}$ & 115 & $48.94 \%$ \\
$\begin{array}{l}\text { I hate speculators who maliciously } \\
\text { raises prices through cornering } \\
\text { sneakers and making massive orders }\end{array}$ & 145 & $61.7 \%$ \\
$\begin{array}{l}\text { I have no harsh feelings for them } \\
\text { I like them because they are the }\end{array}$ & 60 & $25.53 \%$ \\
sources of sneakers & 12 & $5.11 \%$ \\
I am a sneaker seller & 7 & $2.98 \%$ \\
\multicolumn{1}{c}{ Total } & 235 & \\
\hline
\end{tabular}

On the whole, consumers are aware of and strongly dislike market manipulation, namely the sneaker speculators.

Question \#5: What is your behavior in the sneakers market?

\begin{tabular}{lccc}
\hline \multicolumn{1}{c}{ Options } & $\begin{array}{c}\text { Number } \\
\text { of people }\end{array}$ & Proportion & \\
\hline $\begin{array}{l}\text { I only purchase sneakers and never } \\
\text { sell them }\end{array}$ & 160 & $68.09 \%$ \\
$\begin{array}{l}\text { If I won a lucky draw and bought a } \\
\text { pair with original price, I may } \\
\text { sell it on the aftermarket. }\end{array}$ & 48 & $20.43 \%$ \\
$\begin{array}{l}\text { I am not a speculator, but I occasionally } \\
\text { buy sneakers whose prices I assume } \\
\text { will go up and sell them for profit }\end{array}$ & 22 & $9.36 \%$ \\
I am a professional sneaker seller & 5 & $2.13 \%$ \\
\multicolumn{1}{c}{ Total } & 235 & \\
\hline
\end{tabular}


$32.91 \%$ of the consumers who are not professional sellers also sell sneakers. Therefore, the rationality of the sneakers aftermarket trading mechanism must be acknowledged. If market interference were to be implemented, the vested trading mode should not be restricted. "Everyone is both seller and consumer" is an ongoing event in the sneakers aftermarket.

Question \#6: If the government were to supervise the sneakers aftermarket, what would you let the government do?

\begin{tabular}{lccc}
\multicolumn{1}{c}{ Options } & $\begin{array}{c}\text { Number } \\
\text { of people }\end{array}$ & Proportion & \\
\hline $\begin{array}{l}\text { The government should not interfere } \\
\text { with the sneakers market }\end{array}$ & 63 & $26.81 \%$ \\
$\begin{array}{l}\text { The government should influence } \\
\text { the price of sneakers }\end{array}$ & 39 & $16.6 \%$ \\
$\begin{array}{l}\text { The government should supervise the } \\
\text { authentication process of sneakers }\end{array}$ & 60 & $25.53 \%$ \\
$\begin{array}{l}\text { The government should supervise } \\
\text { every aspect of the sneakers market }\end{array}$ & 73 & $31.06 \%$ \\
\multicolumn{1}{c}{ Total } & 235 & \\
\hline
\end{tabular}

Over $73.19 \%$ of the people surveyed support government supervision on the sneakers market in at least one way.

\section{Data Analysis}

\section{1) Descriptive statistical analysis}

To analyze the price-influential factors on the sneaker market, we collected data from Nice, up to $01 / 26 / 2020$, which contains 1000 pairs of sneakers that are popular for sale. Descriptive statistical analysis of the original price, transaction price, transaction volume and demand for sneakers for sneakers on trading platform are shown in Tables $1-4$ respectively.

\section{2) Correlation analysis}

According to Pearson correlation analysis, the correlation coefficient between transaction price and release time is -0.0373 . This shows, the earlier a sneaker was put on sale, the higher its transaction price will be. Namely, the sneaker

Table 1. Descriptive statistical analysis of the original price for sneakers on trading platform (Yuan).

\begin{tabular}{ccccc}
\hline Brand & Average & Maximum & minimum & standard deviation \\
\hline ADIDAS & 1910 & 5999 & 449 & 959 \\
CONVERSE & 747 & 1499 & 339 & 196 \\
JORDAN & 1400 & 2999 & 799 & 302 \\
NIKE & 1096 & 2799 & 549 & 335 \\
VANS & 651 & 1199 & 465 & 139 \\
\hline
\end{tabular}


Table 2. Descriptive statistical analysis of the transaction price for sneakers on trading platform (Yuan).

\begin{tabular}{ccccc}
\hline Brand & Average & Maximum & Minimum & Standard deviation \\
\hline ADIDAS & 2866 & 19,999 & 420 & 2896 \\
CONVERSE & 893 & 8997 & 200 & 749 \\
JORDAN & 2114 & 36,999 & 200 & 3196 \\
NIKE & 1975 & 24,999 & 400 & 2664 \\
VANS & 767 & 7000 & 300 & 1037 \\
\hline
\end{tabular}

Table 3. Descriptive statistical analysis of the transaction volume for sneakers on trading platform (pair).

\begin{tabular}{ccccc}
\hline Brand & Average & Maximum & Minimum & Standard deviation \\
\hline ADIDAS & 309 & 9437 & 0 & 1339 \\
CONVERSE & 5918 & 121,556 & 4 & 13,897 \\
JORDAN & 5995 & 367,531 & 1 & 28,992 \\
NIKE & 3626 & 69,976 & 1 & 7739 \\
VANS & 1708 & 19524 & 14 & 3838 \\
\hline
\end{tabular}

Table 4. Descriptive statistical analysis of the demand for sneakers on trading platform (pair).

\begin{tabular}{ccccc}
\hline Brand & Average & Maximum & Minimum & Standard deviation \\
\hline ADIDAS & 2 & 71 & 0 & 10 \\
CONVERSE & 20 & 150 & 0 & 24 \\
JORDAN & 31 & 486 & 0 & 67 \\
NIKE & 27 & 286 & 0 & 41 \\
VANS & 9 & 61 & 0 & 13 \\
\hline
\end{tabular}

transaction price of those latest one is relatively low. The correlation coefficient between transaction price and selling price is 0.2899 , which shows that transaction price increases as the original price increases. The correlation coefficient between transaction price and transaction volume is 0.0317 , which shows that transaction price increases as transaction volume increases. The correlation coefficient between the transaction price and the demand is 0.1873 , indicating that the higher the demand, the higher the transaction price.

\section{3) Regression analysis}

The transaction price of sneakers on a trading platform is related to the original price, release time, trading volume, demand, brand, and individual characteristics of sneakers, which is also confirmed by descriptive statistical analysis and correlation analysis. Therefore, the regression model is established to further analyze the factors affecting the family price of second-hand sneakers. The model is as follows: 


$$
y=\beta_{0}+\beta_{1} x_{1}+\beta_{2} x_{2}+\beta_{3} x_{3}+\beta_{4} x_{4}
$$

$y$ is the transaction price; $x_{1}$ is the release time; $x_{2}$ is the original price; $x_{3}$ is the trading volume; $x_{4}$ is the demand of sneaker; $\beta_{1}, \beta_{2}, \beta_{3}, \beta_{4}$ are corresponded coefficient of variables; $\beta_{0}$ is a constant.

The transaction price of sneakers was analyzed by regression using Stata software, and the results were shown in Table 5.

\section{4) Conclusion for data analysis}

After correlation analysis and regression analysis, we conclude that the impact of original price on transaction price is positive and significant. The demand also has a significant positive influence on the transaction price. The influence of trading volume on trading price is negative and not significant. The effect of selling time on transaction price is negative and not significant.

As the market obeys the rules, not only prices adjust to clear markets, but so do quantities in the form of supply and demand rationing. Typical examples are unemployment on the labor market and waiting lists in the social housing sector. Unlike competitive equilibria in models without price controls, which are Pareto efficient, equilibria in models with price controls are typically Pareto inefficient, even when restricting attention to allocations that are consistent with the given price controls (Herings, 2018).

\section{Platform Interference-Based Price Control Hypotheses}

To limit the risk in the sneakers market and reduce fluctuations, platforms have the responsibility to interfere with the transactions. According to the analysis, demand and original prices affect sneaker prices most significantly. Regarding the platform's methodology, since the original price is set by the manufacturers, the platform is only able to interfere with the demand, by limiting the number of orders, and the prices directly. The following are two common price control strategies adopted by popular sneakers aftermarket platforms.

1) Price control 1: Conduct speculator control to limit price

Table 5. The regression analysis result of transaction price of sneaker on trading platform.

\begin{tabular}{|c|c|c|c|c|}
\hline Variable & Model 1 & Model 2 & Model 3 & Model 4 \\
\hline release time $\left(x_{1}\right)$ & & & & $\begin{array}{c}-2.04 \\
(0.738)\end{array}$ \\
\hline original price $\left(x_{2}\right)$ & $\begin{array}{l}1.43^{\star * *} \\
(0.000)\end{array}$ & $\begin{array}{l}1.37^{\star * *} \\
(0.000)\end{array}$ & $\begin{array}{l}1.35^{\star * *} \\
(0.000)\end{array}$ & $\begin{array}{l}1.34^{* * *} \\
(0.000)\end{array}$ \\
\hline trading volume $\left(x_{3}\right)$ & & & $\begin{array}{c}-0.01 \\
(0.107)\end{array}$ & $\begin{array}{c}-0.01 \\
(0.107)\end{array}$ \\
\hline demand $\left(x_{4}\right)$ & & $\begin{array}{l}9.40^{* * *} \\
(0.000)\end{array}$ & $\begin{array}{c}11.27^{\star * *} \\
(0.000)\end{array}$ & $\begin{array}{c}11.32^{\star * *} \\
(0.000)\end{array}$ \\
\hline constant & & $\begin{array}{l}-60.66 \\
(0.760)\end{array}$ & $\begin{array}{l}-35.98 \\
(0.856)\end{array}$ & $\begin{array}{c}4093.51 \\
(0.741)\end{array}$ \\
\hline
\end{tabular}


For sneaker market platforms, it is necessary to identify and ban illegal orders and behaviors of illegal accounts, for it is likely that they are caused by speculators. When an account is involved in: a) Generating a huge number of orders in a short amount of time and b) Posting comments about false price information, this account and all orders associated with it should be suspended immediately for further inspection.

However, merely eliminating the speculators does not address the real problem. Though speculation does exist, it is in fact very uncommon in the sneakers aftermarket.

On one hand, the circulation of shoes in the aftermarket is relatively small, so chance for speculation is low. Low liquidity of sneakers also discourages most speculators since they are not able to allocate their positions quickly enough. On the other hand, speculation requires big cash, and most speculators would prefer a position in the stock market, only a few of them are active in the sneakers market.

2) Price control 2: Limiting fluctuation

Directly controlling prices may potentially be another valid method. We examine a particular group of price fluctuations encountered on certain sneakers in many platforms. Administered prices and price ceilings on different sneakers in secondary trading might ease the situation. It turns out that popular sneakers' prices particularly fluctuate around $\pm 10 \%$ in stable cases, but larger fluctuation may occur during major events related to the sneakers (e.g. release day or restock) or when speculation is conducted. Intense fluctuations usually bring intense profit for some and loss to others who are mostly ordinary consumers. Therefore, a price ceiling and floor could stabilize the market and prevent consumers from being reaped (Reisinger et al., 2018).

However, platforms tend to be unwilling to set price ceilings and floors. One reason is that the specific standard is difficult to determine. A low-price ceiling or a high price floor could both affect the sneakers market negatively. Another reason is that the platforms who rely on transaction fees will lose profit if they encounter declined orders due to price control.

Surveys show another aspect of sneaker aftermarket problem other than prices: transportation and authentication. The real problems are analyzed by the trading rules and mechanisms from the three biggest sneaker trading platforms of the world, we found that problems always happen during the transaction process.

While China has the world's biggest counterfeit products output, almost 20 times more than Turkey who comes second, transparency and authentication of trading goods turn out to be the biggest problem rather than price premium. The survey also supports the conclusion that speculation and price premium are not the major problems in the sneaker's aftermarket. About $58 \%$ of people buy sneakers they want, with a tolerance for price premium of more than $200 \%$. In terms of consumer satisfaction, reducing counterfeits and improving transaction transparency are more important than merely controlling the prices. 


\section{Market Mechanism-Based Block Chain Strategy}

There is in fact another strategy other than price control for the platforms to adopt that could potentially improve consumer satisfaction and the health of the market environment-block chain technology. Instead of interfering with the market, block chain technology fully grants freedom to the market and the price mechanism, but in the meanwhile addresses other major problems effectively.

Block chain tech has certain advantages that perfectly aligns with the needs for transparency of the sneakers market, making it the most desired technology. Block chain is an IT terminology that consists of "blocks" and "chains". A system of block chain is basically a shared data database where any changes are documented by all users in the p2p network system onto the blocks. By design, a block chain is resistant to modification of the data. It is "an open, distributed ledger that can record transactions between multiple parties efficiently and in a verifiable and permanent way" (https://www.ibm.com/blockchain/what-is-blockchain). Therefore, block chain has the following advantages that we think may be compatible with the sneakers aftermarket trading system:

Transparency. Transparency is one of the most renowned features of blockchain, and it does not just mean that every user is able to acknowledge what has been added to or adjusted in the block. All network participants have access to the distributed ledger and its immutable record of transactions. With this shared ledger, transactions are recorded only once, eliminating the duplication of effort that is typical of traditional business networks. If a transaction record includes an error, a new transaction must be added to reverse the error, and both transactions are then visible. When examining a block, a user can easily track its initial phase, and for sneakers consumers, they will be able to verify who, when, and where the sneakers they own are manufactured. Likewise, every trade, authentication, and logistic information of the sneakers can be accessed by their owner.

Security. Security is brought by encryption, an innate element of the block chain. This paper will not discuss the specific technological details of the encryption of blockchain, but to be general, each block contains a cryptographic hash of the previous block, a timestamp, and transaction data. Also, every user participating in the blockchain system will need to be approved with their ID before they have access to the blocks. (Authenticators will need their credentials.) With proper coding, blockchain would potentially secure the transactions and authentication data of a pair of sneakers, which prevents such swapping. Another innate element of blockchain prevents hacking: multi-point backup. In a blockchain network the information of a block is not only kept by one participant but all participants involved, creating backups for a block under all the accounts involved. If one joint of a block gets breached and its information is changed, it will create a mismatch with other users' data, which then will provide evidence for hacking. It is practically impossible for a hacker to change any data in a block without being noticed by other users in the network.

1) A proposed block chain design for the sneaker market will be effective. The 
construction revolves around the concept that a pair of sneakers is a block.

The essence of the sneakers block chain design is a customized and standardized chip that should be inserted to the sneakers by the first seller who wants to sell the pair on the aftermarket. This is not exactly the best plan, since standardization would be difficult without the sneaker manufacturers' (like Nike) direct authorization. However, sneaker manufacturers will likely not accept to add a chip that does not bring them profit and vainly increase cost. Therefore, the distributor of the chip will likely be a third-party chip company or the platforms themselves. One benefit of platform-sponsored block chain chips is they encourage competition and urges platforms to refine their block chain services. No matter if it is the platforms or third-party chip companies that provide the block chain chips, the market will stabilize once it accepts the block chain system and the best single type of standardized chip will stand out after competition.

Step 0: Registration of the seller. He/she needs to provide I.D. and all legal information about him/herself.

Step 1: The first seller, named User 1 on the chart, will purchase, or be provided with the chip and insert it underneath the insole.

Step 2: Upload the sneakers' information, including their label number, shoebox I.D., and photos. Up to this point, the chip has become the one and only corresponding pass to the block chain system of the sneakers. It would not be possible to change the information once the registration is complete.

Step 3: Link the user's verification to the sneakers, verify the ownership.

Step 4: Make the sneakers "on sale". Provide the order number of the platform.

Step 5: Ship to platform. The logistics company registers itself and the package track number as well as the shipping and delivery date.

Step 6: The platform receives the sneakers. The authenticator registers him/herself and begins authentication. If the sneakers are genuine, the transaction continues.

Step 7: The platform ships the sneakers to the buyer, which is User 2. The logistics company repeats Step 5 .

Step 8: The buyer, which is user 2, receives the sneakers, verifies the sneakers information (uploaded in Step 2), and registers his/her legal information as the current owner of the sneakers (Figure 1).

During the entire transaction process, nothing is quite different to what sneaker purchases are nowadays without the block chain network. However, the network made the transaction dramatically different. Participants in this network include: the seller, the logistics company, the platform, the authenticator, and the buyer. Each participant serves as a joint that has the access key to viewing every information in the block they own as a backup, yet they have limited access to altering the information: only when they are supposed to.

2) Even with such a complete block chain network, there will be times when something goes wrong, and that is when a supervisory mechanism is needed. For counterfeits, swapping, and sneakers market manipulation, the supervisory 


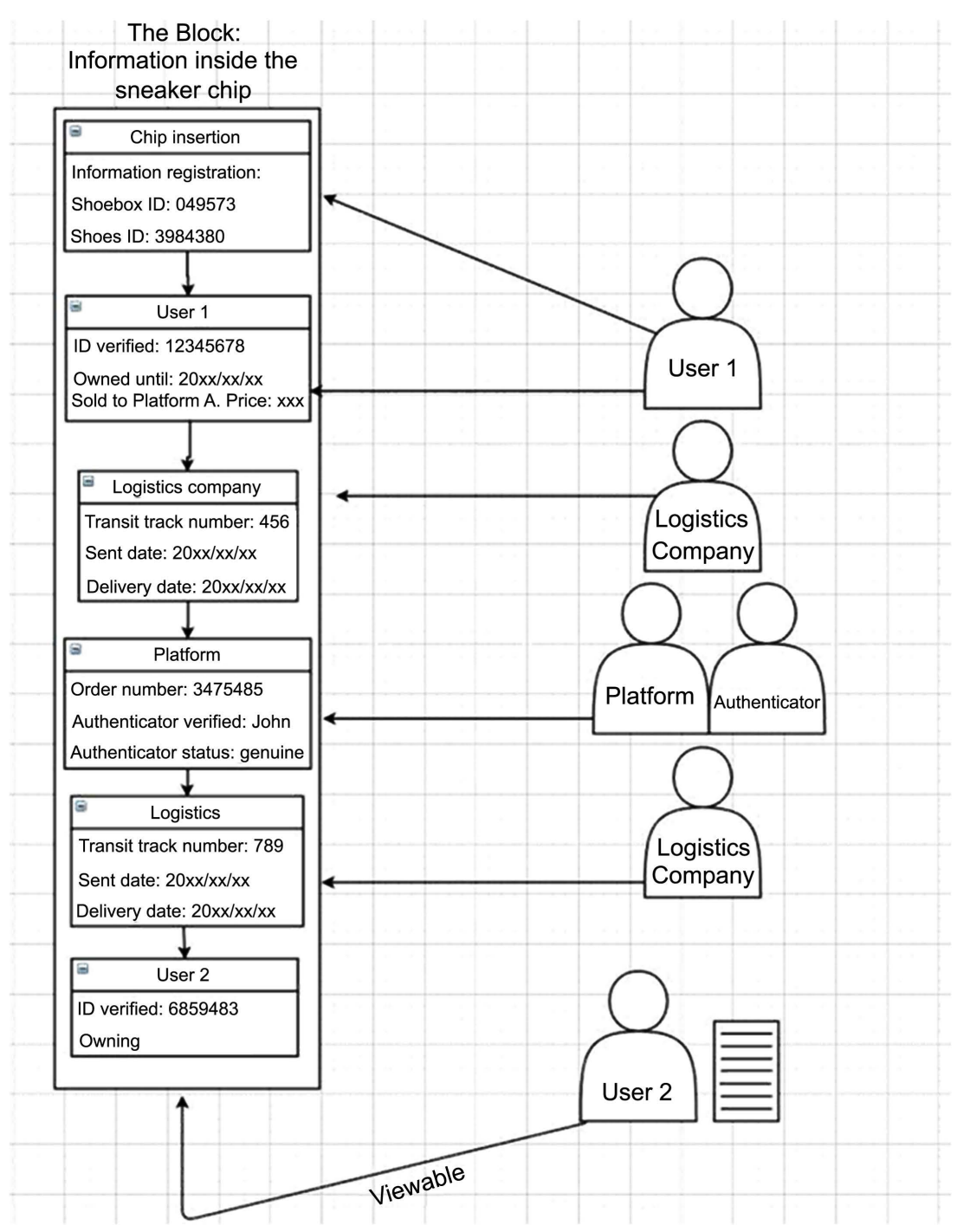

Figure 1. The schematic diagram from the seller to a buyer through block chain.

mechanism of the block chain network will be precisely aimed at those problems and introduce an arbitration group, a third-party investigation team, and a credit system exclusively for such purposes.

\section{a) Counterfeits}

Usually identified as "fake shoes", counterfeit sneakers are the major problem in the sneakers aftermarket. The existence of counterfeits spurred the founding of several platforms and a job called authenticators. The usual case of identifying a pair of fake sneakers is through the platform's authenticator. During the transaction, if the authenticator identifies the sneakers as "fake", a series of arbitration and inspecting processes are launched. First, an arbitration group consisting of authenticators will each inspect the sneakers to reassure its authenticity. If it turns out to be the first authenticator's mistake, then the transaction proceeds. If the pair were fake, we narrow down the responsibility to either the logistics company or the seller. To precisely find out the guilty, the investigation 
team would contact the logistics company to see if anything went wrong during shipping. The investigation will be easy since all the information is uploaded to the blockchain network. Under the modern system of logistics and the blockchain network it would be impossible to open the package, swap the sneakers, and move the chip without creating information mismatches on the block backups, especially when the logistics company has an exclusive distribution center for the platform. If there were swapping, the next section will explain. The seller would be guilty if no swapping happened: a guilty seller's account will be instantly destroyed, and the same I.D. and IP address will be banned from any future sneakers transactions. The information of the guilty seller will be uploaded to a credit system where every buyer, seller, and platform in the sneakers market can view, and the blacklist will be permanent. The seller would be handed over to the police if the case is serious or involves large numbers of sneakers. As for the sneakers, the information of that fake pair will go onto the black list as well. The chip will be formatted and recycled.

After a successful transaction, if a buyer chooses to double check and re-authenticate the sneakers by a different authenticator, which will also be documented to the block, and finds out the sneakers are fake, the arbitration process repeats. If the sneakers were genuine, the second authenticator will lose credit points on the credit system. If the sneakers were fake, the first authenticator will be fired by any platform that hired him/her and banned from future authentication works. His/her information will be uploaded to the black list as well. This protocol will also operate when an authenticator loses all his/her credit points. The rest of the process will be the same as what is mentioned in the last paragraph to find out the source of the fake pair.

b) Swapping.

As previously mentioned, swapping will be extremely unlikely. If such an incident happens, the police will directly take over the case since it is almost certain that bribing and corruption are involved.

c) Market manipulation

To get rid of manipulation, individual buyers' and sellers' accounts must be restricted to buying or selling a small number of sneakers every day. Sellers registered as firms can enjoy looser restrictions. No buyer can be registered as a firm, and purchasing only a few sneakers a day will be allowed. Orders that surpass the restriction will be postponed to the next day or banned. Any account that persistently tries to order large numbers of sneakers will go to the blacklist. What's more, bots must be banned by technological means. No bot will be able to register multiple sellers or buyers with different I.D.s. ReCAPTCHA or similar technologies could solve this problem. With these precautions, no one with large cash will be able to manipulate the prices of the sneakers.

d) The Blacklist

The Blacklist is the essential part of the credit system. Personnel and accounts on the blacklist will not have access to the block chain network. 


\section{Conclusion}

Using stsatistical methods, questionnaires, and a deep interview as several perspectives in the sneaker trading platform, the paper finds out that a common concern on the price-premium may be rational, while the noticeable issues are about the transparency transaction.

By the statistical analysis of price-influential factors, our paper finds two factors that can significantly affect the price of sneakers on sale, which are original price and demand. Our research analyzes two hypotheses that may address the price-premium: Limiting price fluctuations to decrease the demand, which has downsides for the development of the sneaker market. Also, it is impossible to decrease the sneaker's original price, from a sports brand's perspective.

During the interview and questionnaire, which includes the largest group of consumers on popular consumption, our paper found that most of them care for the authenticity and transparency of the trading process. Therefore, we want to utilize the block chain technology to address the problem, since all roles involved in the trading process can be tracked and recorded through a chip put in the shoe box, so that we can find corresponding parts when problems appear.

In addition, there are many other sneaker secondary market trading rules and means to supervise the market more effectively, such as the platform's access conditions for sneaker sellers like personal ID, or the intervention of the government's third-party organization-China Certification and Inspection Group (CCIC).

As the trust among the buyer, the seller, and the trading platform can be enhanced through block chain, it is inevitable that the sneaker market will have a preposterous future.

In the future, we will establish a more optimized theoretical model and collect more representative data to analyze the price mechanism of the sneakers aftermarket. The goal is to establish a more complete and more transparent market mechanism to ensure the rational operation of the sneakers aftermarket.

\section{Conflicts of Interest}

The authors declare no conflicts of interest regarding the publication of this paper.

\section{References}

Herings, P. J. (2018). Equilibrium and Matching under Price Controls. Journal of Economic Theory, 177, 222-244. https://doi.org/10.1016/j.jet.2018.06.004

https://tech.sina.com.cn/roll/2020-02-25/doc-iimxyqvz5692240.shtml

https://www.huxiu.com/article/312230.html

https://www.ibm.com/blockchain/what-is-blockchain

Reisinger, M., Romero, L. S., \& Zenger, H. (2018). Parallel Imports, Price Controls, and Innovation. Journal of Health Economics, 66, 163-179.

https://doi.org/10.1016/j.jhealeco.2019.05.002 